\title{
A PRELIMINARY STUDY ON ULTRASONIC TREATMENT EFFECT ON TRANSVERSE WOOD PERMEABILITY
}

Takashi Tanaka ${ }^{1}$,Stavros Avramidis ${ }^{2}$, Satoshi Shida

\begin{abstract}
Ultrasonic pre-treatment of small and pressure saturated Douglas-fir heartwood specimens at 20 $\mathrm{kHz}$ fixed frequency with an acoustic horn resulted in increased specific permeability coefficient in both radial and tangential directions. Statistical analysis revealed that there was a high correlation between ultrasonic treatment time and specific permeability coefficient. Improvement rate of permeability in both radial and tangential directions was nearly the same regardless of treatment time.
\end{abstract}

Keywords: Douglas-fir, ultrasound, radial, tangential, air flow

\section{INTRODUCTION}

Wood permeability is a measure of the ease with which fluids flow through the wood under a static or dynamic pressure differential. Bulk flow in wood, such as impregnation of wood with stabilizers, preservatives and pulping agents, and diffusion, such as drying or fumigation, are interrelated to wood permeability levels (Siau 1995). Improved permeability in wood may lead to faster, cheaper and high-quality drying, easier chemical treatment, and effective manufacturing of wood-polymer composites.

Transverse permeability, which is much more important than longitudinal permeability in relation to bulk flow and diffusion in timber, is however much smaller than that of the longitudinal direction due to the anisotropic structure of wood. Permeability ratios of longitudinal/transverse are 15 to 500,000 in several softwood species in North America (Comstock 1970). In addition, permeability of heartwood is generally smaller than that of sapwood (Siau 1995). Furthermore, differences between radial and tangential direction (normally a ratio of 2:1 between the two) can also cause problems in processing that can result in incomplete and/or significantly variable treatments between and within timbers or $\log s$ in a treatment facility.

Douglas-fir (Pseudotsuga menziesii) is one of the most important species in Canada, extends from the Rocky Mountains to the Pacific Coast and from Mexico to central British Columbia, and is used mostly for building and construction purposes and in the manufacture of various products (Anonymous 1999). But radial permeability of Douglas-fir has low permeability compared to other commercially important softwood species in North America, such as spruce (Picea), pine (Pinus), fir (Abies), or redwood (Sequoia) (Comstock 1970).

The drying of wood results in high capillary forces as the moisture content decreases from the green condition to the fiber saturation point. Due to those forces, a large number of cell-wall pits

\footnotetext{
'Biomaterial Sciences Department, Graduate School of Agricultural and Life Sciences, The University of Tokyo, 1-1-1 Yayoi, Bunkyo-ku, Tokyo 113-8657, Japan

${ }^{2}$ University of British Columbia, Department of Wood Science, Vancouver, BC, V6T 1Z4, Canada Tel. +1 604

8226153; Fax +1 6048229104 Corresponding author: stavros.avramidis@ubc.ca

Received: 29.10 .2009 . Accepted: 29.12.2009.
} 
become aspirated during drying which in turn reduce the permeability of wood and therefore increases the difficulty of fluid impregnation (Comstock 1968). If the aspirated pits are removed from the aspirated position in some method, permeability of wood should be increased.

Ultrasound, which is sound with a frequency greater than the upper limit of human hearing, is widely used for food processing such as sterilization, extraction, freezing and filtration to reduce processing time and to increase efficiency (Mason 1996). Soloff (1964) investigated the ultrasonic effect on drying rate with various materials, and he found that the drying rate of wood flour was increased with ultrasound. Burdell and Barnett (1969) showed that shock-waves in a pilot cylinder under proper pressures were effective as a means to accelerate injection of liquid preservatives into wood lumber. Avramidis (1998) investigated the effect of ultrasound on the absorption of some chemicals by Douglas-fir (Pseudotsuga menziesii), sitka spruce (Picea sitchensis), and ponderosa pine (Pinus ponderosa), and he reported that ultrasound enhanced the absorption of CCA and pentachlorophenol in small sapwood specimens under atmospheric pressure.

In this study, the effect of ultrasonic treatment on the resultant air permeability was evaluated for small Douglas-fir heartwood.

\section{MATERIALS AND METHODS}

One hundred and twenty air-dried matched specimens of $6 \mathrm{~mm}$ in thickness and $30 \mathrm{~mm}$ by 30 $\mathrm{mm}$ in width and length were cut from Douglas-fir heartwood (Figure 1). For half of them the thickness direction was in the wood radial axis and for the other half in the tangential axis. Dimensions were accurately measure with a pair of digital calipers.

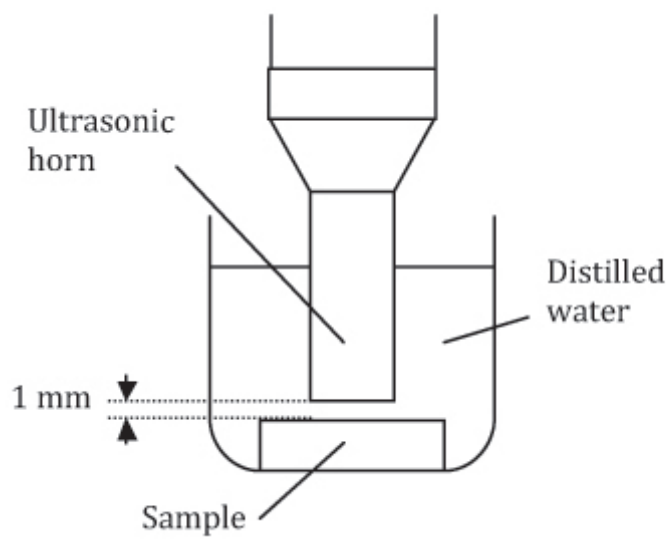

Figure 1. Schematic of ultrasonic treatment

At first, one hundred specimens were saturated with distilled water by using a vacuum-pressurevacuum cycle and then left immersed for at least three days (verified visually by lack of flotation), in an evacuated glass container. Next, while still in distilled water, they were treated by ultrasound with frequency of $20 \mathrm{kHz}$ and with an amplitude of $300 \mathrm{~W}$ at a distance of about $1 \mathrm{~mm}$ from the ultrasonic horn (Model 500 Ultrasonic Dismembrator, Fisher Scientific, Hampton, USA) still in distilled water for 0 (control), 10, 20, 40, and 80 minutes (Figure 1). Thereafter, they were placed in a conditioning chamber (Parameter Generation \& Control, CL-5488F) at a condition of $20^{\circ} \mathrm{C}$ and $65 \%$ relative humidity for two weeks.

PVC tubes of $21 \mathrm{~mm}$ of inner and $27 \mathrm{~mm}$ of outer diameter were glued on both sides of all the specimens with epoxy resin adhesive (Industrial Formulators, Inc., Port Coquitlam, Canada) to 
allow for proper attachment to the permeability measuring apparatus (Figure 2). Furthermore, all edge surfaces of each specimen were also sealed to make sure that air flow was along the thickness direction, only. Furthermore, microscopic examination of cross-sections revealed minimum penetration of the epoxy resin and thus no effect on the effective cross-sectional area.
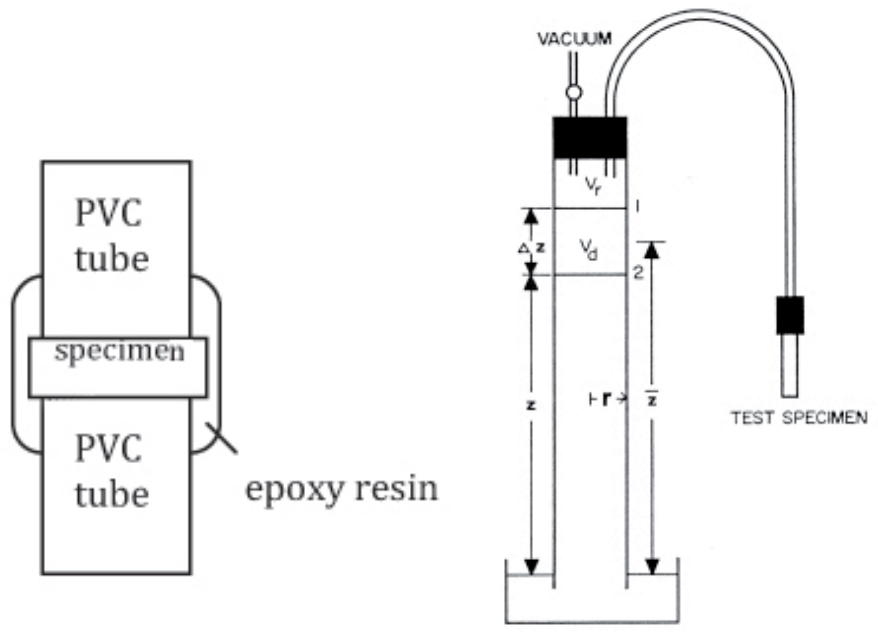

Figure 2. Schematic of permeability specimen (left) and the falling-water apparatus (right - from Siau 1995)

Air permeability of each specimen was measured by the falling-water displacement method using an apparatus shown in Figure 2 (Siau 1995) that has been used extensively over the last 25 years and has been found to provide repetitive permeability values of comparative nature. The square crosssection specimens were fitted in the high vacuum ruber hose holder and secured by four hose clamps. The tightness of the system was tested with an aluminum sample of the same dimensions frequently. The water level decline was measured for about 24 hours with each sample. Thereafter, gas permeability coefficient was calculated using equations (1) and (2). For the $\mathrm{P}_{\text {atm }}$ of these equations, the average of the atmosphere pressure at the start and at the end of the measurement was used because the atmospheric pressure changed during measurement.

$$
k_{g}=\frac{\alpha V_{d} C L\left(P_{a t m}-\beta \bar{z}\right)}{\beta t A \bar{z}\left(P_{a t m}-\gamma \bar{z}\right)}
$$

where, $k_{g}$ is the superficial gas permeability coefficient, $\left(\mathrm{m}^{2} / \mathrm{Pa} \mathrm{s}\right) ; V_{d}$ is displacement volume $\left(\mathrm{m}^{3}\right)$; $C$ is determined by equation $2 ; L$ is the thickness of the sample $(\mathrm{m}) ; \stackrel{d}{P}_{a t m}$ is the atmosphere pressure $(\mathrm{m} \mathrm{Hg}) ; z$ is the distance as presented in Fig. 2 (m); $t$ is falling time (s); $A$ is the inner area of the PVC tube $\left(\mathrm{m}^{2}\right)$; and values of $\alpha, \beta$ and $\gamma$ are given in Siau (1995).

$$
C=1+\frac{\beta V_{r} z}{V_{d}\left(P_{a t m}-\beta \bar{z}\right.}
$$

where, $\Delta z$ is change in height of water during time $t(\mathrm{~s})$. 

tion 3 .

The gas permeability coefficient was converted to specific permeability coefficient by equa-

$$
K=\eta \cdot k_{g}
$$

where, $K$ is specific permeability coefficient $\left(\mathrm{m}^{2}\right)$. In this work, we will be reporting on the behavior of $K$ which is independent of the fluid used to measure it and $\eta$ is the air viscosity at $20^{\circ} \mathrm{C}\left(1.81 \times 10^{-5}\right.$ Pa s).

\section{RESULTS AND DISCUSSION}

Figure 3 shows the relationship between $\mathrm{K}$ and ultrasonic treatment length in the radial and tangential directions including standard deviation. For comparison purposes, the controls, namely, no/ yes water immersion and no ultrasonic treatment are included.



Figure 3. Relationship between ultrasound treatment time and specific permeability coefficient in radial and tangential direction

The average $K$ value of non-treated radial specimens was about $1.86 \times 10^{-18} \mathrm{~m}^{2}$ whereas the one with water immersion for 72 hours was about $1.80 \times 10^{-18} \mathrm{~m}^{2}$. The difference was not statistically significant amongst the two demonstrating that 72 -hour water immersion did not affect air permeability. However, after ultrasonic treatment, $K$ values in the radial direction increased in a direct fashion. Specific permeability coefficient in the radial direction significantly increased at the $1 \%$ level as ultrasonic treatment time increased between 10 and 80 minutes. (Table 1). 
Table 1. ANOVA of the relationship between ultrasound treatment time and specific permeability coefficient in the radial direction

\begin{tabular}{lrrrrrr}
\hline \hline & $\begin{array}{c}\text { sum of } \\
\text { squares }\end{array}$ & $\begin{array}{c}\text { deg of } \\
\text { freedom }\end{array}$ & $\begin{array}{c}\text { mean of } \\
\text { squares }\end{array}$ & F value & $\begin{array}{c}1 \% \text { significance } \\
\text { level }\end{array}$ \\
\hline Between-group & 4049.26 & 4 & 1012.31 & 458.87 & $>$ & 3.77 \\
\hline Within-group & 99.27 & 45 & 2.21 & & & \\
\hline total & 4148.53 & 49 & & & & \\
\hline \hline
\end{tabular}

The average $K$ value of non-treated tangential specimens was about $0.98 \times 10^{-18} \mathrm{~m}^{2}$ whereas the one with water immersion for 72 hours was about $0.83 \times 10^{-18} \mathrm{~m}^{2}$. The difference was not statistically significant amongst the two indicating that current water immersion did not affect air permeability. However, after ultrasonic treatment, $K$ values in the tangential direction increased in a direct fashion. Specific permeability coefficient in the tangential direction significantly increased at the $1 \%$ level as ultrasonic treatment time increased between 10 and 80 minutes. (Table 2).

Table 2. ANOVA of the relationship between ultrasound treatment time and specific permeability coefficient in the tangential direction

\begin{tabular}{lrrrrrc}
\hline \hline & $\begin{array}{c}\text { sum of } \\
\text { squares }\end{array}$ & \multicolumn{1}{c}{$\begin{array}{c}\text { deg of } \\
\text { freedom }\end{array}$} & $\begin{array}{c}\text { mean of } \\
\text { squares }\end{array}$ & F value & $\begin{array}{c}1 \% \text { significance } \\
\text { level }\end{array}$ \\
\hline Between-group & 934.86 & 4 & 233.72 & 817.71 & $>$ & 3.77 \\
\hline Within-group & 12.86 & 45 & 0.29 & & & \\
\hline total & 947.72 & 49 & & & & \\
\hline \hline
\end{tabular}

Figure 4 shows linear regressions for the relationship between ultrasonic treatment time and $K$ in the radial and tangential directions and a high correlation between ultrasound treatment time and $K$ both in radial and tangential direction $\left(\mathrm{R}^{2}=0.96\right.$ in radial, and $\mathrm{R}^{2}=0.97$ in tangential) is evident. It also reveals that radial permeability is always about two-times larger that the tangential at all cases with and without ultrasonic treatment.

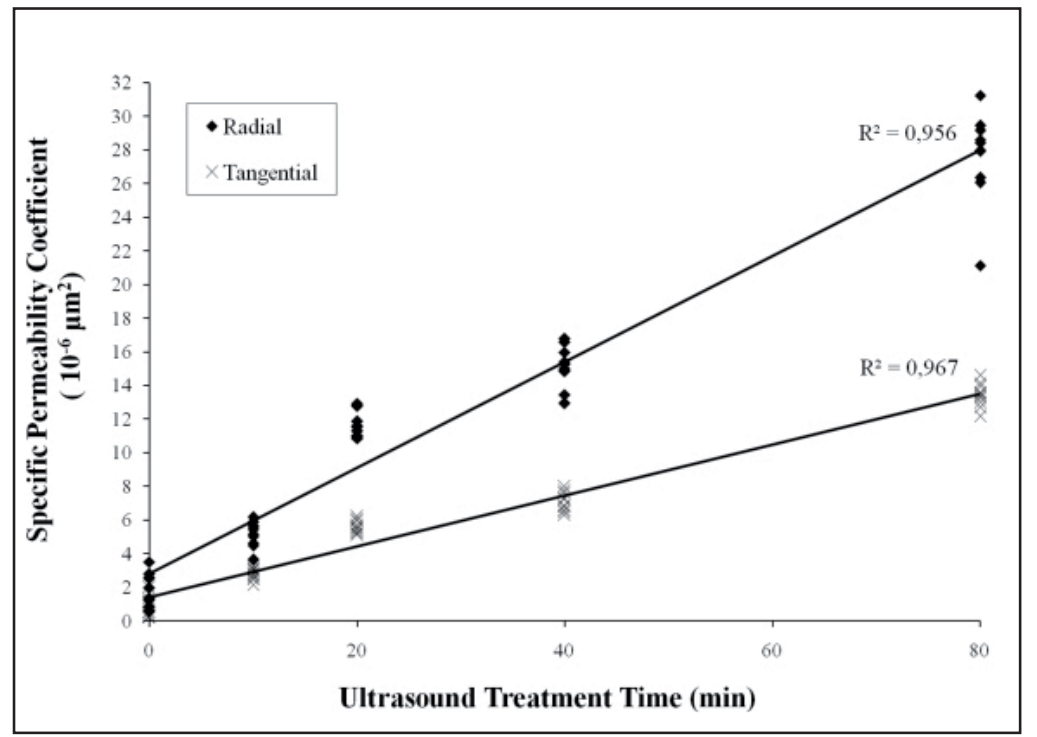

Figure 4. Linear regressions for the relationship between ultrasound treatment time and specific permeability coefficient 
In Figure 5, plots of the ratio of permeability after ultrasonic treatment to that before treatment for both radial and tangential directions are shown and trends are quite conspicuous. For instance, the specimens treated with ultrasound for 80 minutes were 15.3 times more permeable than those with no ultrasound treatment in the radial direction, which is almost same as in the tangential direction (16.2 times). In both cases, the ratio increased with the length of treatment. This is probably a result of a greater number of pit openings due to acoustic vibrations that cause a net permeability increase. The improvement rate of permeability in the radial direction was almost same as that in the tangential direction regardless of treatment time thus indicating no particular difference along the two transverse directions.

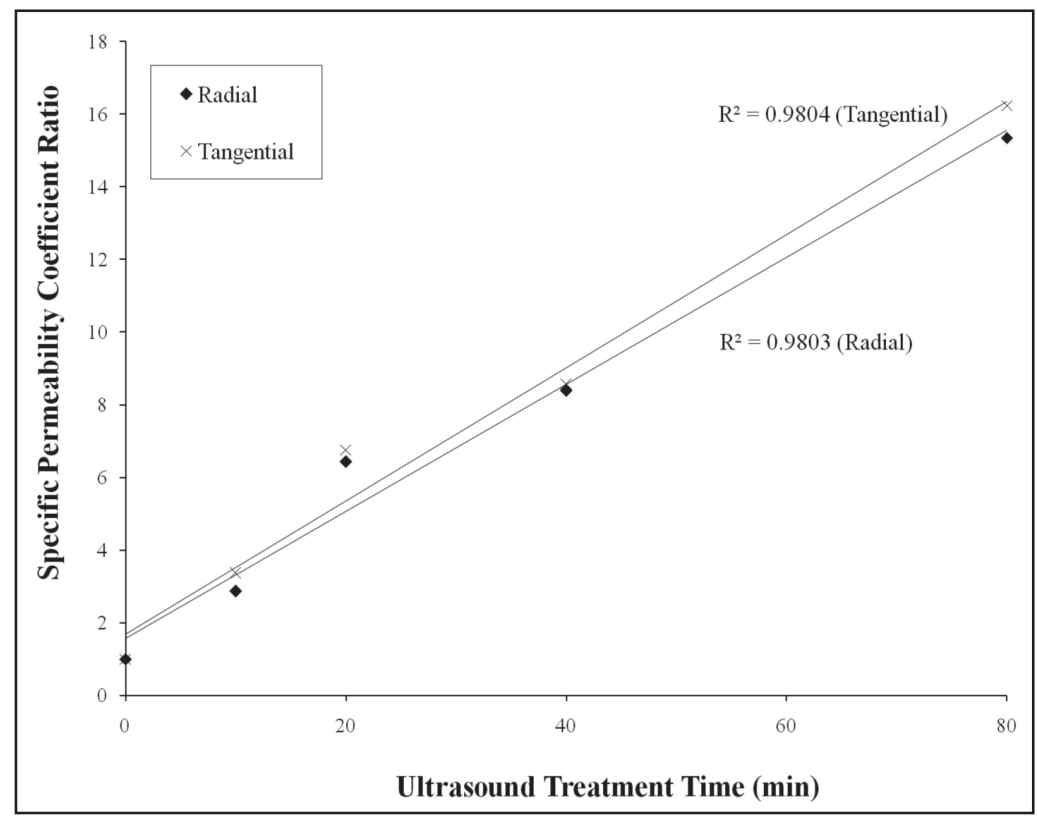

Figure 5. Ratio of permeability after ultrasound treatment to that before ultrasound treatment

Over all, the ultrasonic treatment significantly improve the longitudinal rate of flow of air through wood and this is speculated to be the result of pit de-aspiration and/or destruction of the pit margo/torus system by the sonic forces. Either is capable of increasing the permeability coefficient of wood as summarized by Siau (1995). However, the reader should keep in mind that the trends observed here apply to only thin specimens. Full-size boards might require much greater power inputs and longer treatment times. Therefore, generalization of the current findings should be avoided unless further research is carried out.

\section{CONCLUSION}

Ultrasonic treatment of small saturated Douglas-fir specimens at $20 \mathrm{kHz}$ resulted in statistically significant increased specific permeability coefficients of Douglas-fir heartwood in both radial and tangential directions. Improvement rate of permeability in both radial and tangential directions was almost the same regardless of treatment time. De-aspiration of pits and/or rapture of he margo/ torus system are speculated to be the reasons for such trend. 


\section{REFERENCES}

Anonymous. 1999. Wood handbook - wood as engineering material. USDA - Forest Products Lab. Madison, Wisconsin. Pp. 1-10.

Avramidis, S. 1998. Experiments on the effect of ultrasonic energy on the absorption of preservatives by wood. Wood Fiber Sci. 20(3): 397-403.

Burdell, C. A.; Barnett, J. H. 1969. Pilot plant evaluation of shock-wave pressure treatments. Proceedings of the American Wood Preservers' Association. pp. 174-189.

Comstock, G. L. 1968. Factors affecting permeability and pit aspiration in coniferous sapwood. Wood Sci. Technol. 2: 279-291.

Comstock, G. L. 1970. Directional permeability of softwoods. Wood Fiber Sci. 1(4): 283-289.

Mason, T. J.; Paniwnyk, L.; Lorimer, J. P. 1996. The use of ultrasound in food technology. Ultrasonics Sonochem. 3: S253-S260.

Siau, J. F. 1995. Wood: Influence of moisture on physical properties. Virginia Polytechnic Institute and State University. Pp. 39-58.

Soloff, R. S. 1964. Sonic drying. J. Acoust. Soc. Am. 36(5): 961-965. 